\title{
AUTOMATIC LIFE SAVING SYSTEM USING GSM AND GPS TECHNOLOGY
}

\author{
I. Rajani Kumari \\ Assistant Professor, Department of Electronics and Communication, \\ Sanskrithi School of Engineering, Andhra Pradesh, India \\ Swapna. DV \\ Sanskrithi School of Engineering, Andhra Pradesh, India
}

\begin{abstract}
ABTRACT
Health related issues and parameters are of utmost important to man, and are essential to his existence. This paper presents a system that is capable of providing real time remote monitoring of the heartbeat with improvements of an SMS alert through Global System for Mobile communication (GSM) and a voice call to ambulance in case of emergency that the person is alone and effected by heart attack. This project aims at the design and implementation of a low cost but efficient and flexible heartbeat monitoring and alert system using Global Positioning System (GPS) and Global System for Mobile communication (GSM) technology. In this project heartbeat and temperature of body is measured by sensors which sends the signals to the Control unit and displays on Liquid Crystal Display (LCD), after proper processing and determination of heartbeat rate. If that rate is maximally exceeding the threshold range, immediately the car will stop and blow horn continuously and simultaneously proceeds to an SMS alert will be sent to the nearest medical care centers and to the family, and the same message is converted as voice call and sent to ambulance. Keywords-Control Unit, GPS, GSM, LCD, threshold, voice call.
\end{abstract}

Keywords: Arduino Mega 2560, GPS Module, GSM Modem, Pulse Sensor, Temperature Sensor.

Cite this Article: I. Rajani Kumari and Swapna. DV, Automatic Life Saving System using GSM and GPS Technology, International Journal of Electronics and Communication Engineering and Technology, 10(2), 2019, pp. 01-07.

http://iaeme.com/Home/issue/IJECET?Volume $=10 \&$ Issue $=2$ 


\section{INTRODUCTION}

In today's fast-moving world, human body is getting more prone to heart related disease and there is an increase in number of deaths due to heart diseases. In many countries most of the time heart disease problems harm the elderly persons. Very frequently they live with their own and no one willing to monitor them for 24 hours a day. A stroke occurs when the blood supply to part of brain is interrupted or reduced within minutes brain cells begin to die and some symptoms such as trouble with speaking, paralysis or numbness of the face or and leg. Due to recent research when heart pulse is greater than BPM (beats per minute) then there is a chance $26 \%$ of occurrence of heart attack and it may lead to death.

Indeed this paper, We can save the person life with single touch. In previous papers, person who got an heart attack at that time with the help of hand watch they can sent the SMS only through the GSM. While the person is not in the conscious stage there is more chances the person may lead to death before the person reaching to the hospital. To overcome this problem our paper suggest one touch life extricating system, with the single touch the person will be save who got an heart attack, and the sensors are designed to read pulses of the person in $\mathrm{BPM}$ (beats per minute) and sends the information to the controller and the whole work can be done through GPS, with the help of call converter, SMS will convert to call and call a is initiated to emergency number(108 in INDIA) with GPS location for help. At the same time SMS will be send to the person relatives. By this the doctor knows the heart rate of the person, temperature and condition of the person before reaching to the hospital. By this even some of the deaths can be avoided.

\section{BLOCK DIAGRAM}

The block diagram consists of different components interfacing to a microcontroller. The block diagram is shown in figurel.

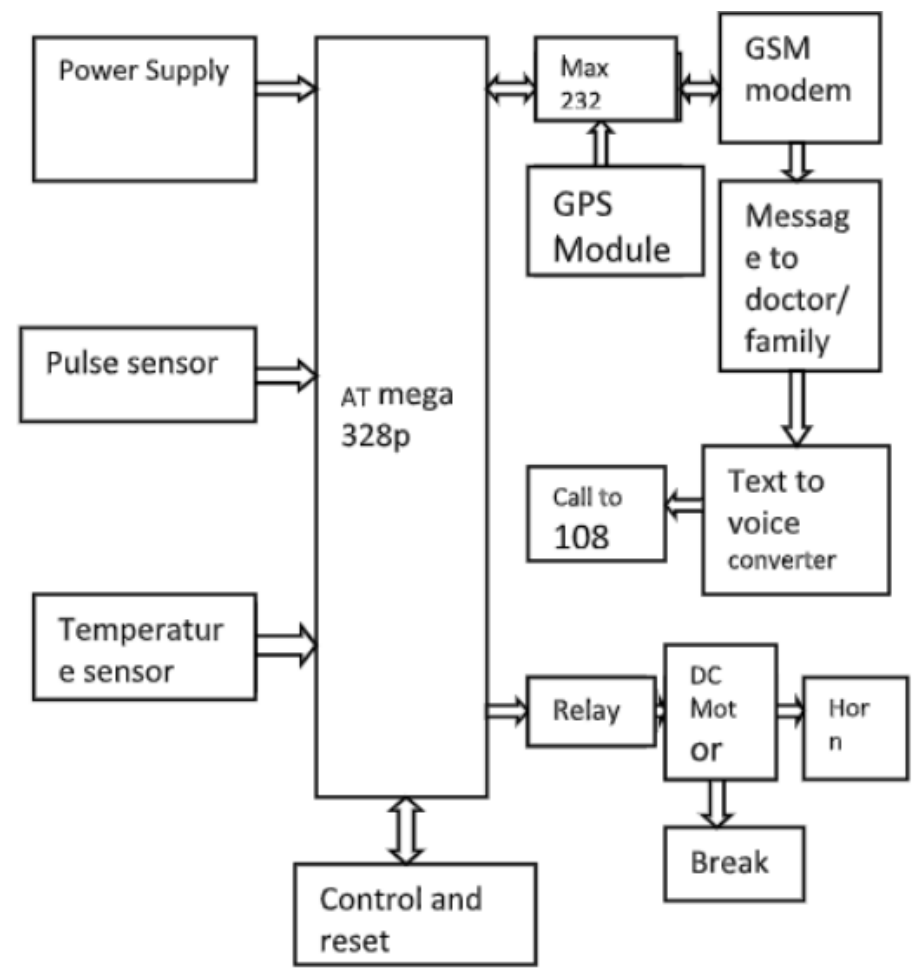

Figure 1 Block Diagram 
The various components in the block diagram are mentioned below:

1. Pulse sensor

2. Temperature Sensor LM35

3. ATmega328p (Arduino UNO)

4. Power Supply

5. Control Unit

6. 16X2 Liquid Crystal Display (LCD)

7. DC motor

8. MAX 232

9. GSM Module

10. GPS module

\subsection{Pulse Sensor}

The pulse sensor or heartbeat sensor has two sides on one side LED is placed along with ambient light sensor and other side we have circuitry which is used for amplification and noise cancellation the LED on the front side of the sensor is placed over a vein in human body. This can be either your finger tip or ear tips but it should be placed directly on top of a vein. Now LED emits light which will fall on to the vein directly the veins will have blood flow inside them only when the heart is pumping, so if we monitor the flow of blood we can monitor the heart beats as well, if the flow of blood is detected then the ambient light sensor will pick up more light since they will be reflected by the blood this minor change in received light is analyzed over time to determine our heart beats. the sensor can operate at $+5 \mathrm{v} / 3.3 \mathrm{v}$ once power connected the signal pin to the ADC pin of the micro controller to monitor the change in output voltage.

\subsubsection{Features}

Operating voltage: $+5 /+3.3 v$.

Current consumption: 4mAmps.

Plug and play type sensor with amplification noise cancellation circuit.

3 pins: ground, VCC, signal.

The VCC connected to $+5 \mathrm{v} /+3.3 \mathrm{v}$ power supply ground connected to $0 \mathrm{~V}$ signal pin will generate pulsating output signal.

\subsection{Temperature Sensor}

LM35 is an analog linear temperature sensor whose output voltage varies linearly with change in temperature. The LM35 is the temperature sensor used in our paper to measure temperature with an electrical output comparative to the temperature (in ${ }^{\circ} \mathrm{C}$ ). It can measure temperature more correctly with a Thermister This generates a high output voltage than thermocouples and may not need the out[put voltage is amplified the scale factor is $0.01 \mathrm{v} /{ }^{\circ} \mathrm{C}$.the $\mathrm{LM} 35$ does not need any exterior calibration and maintains an exactness of $+/-0.4^{\circ} \mathrm{C}$ at room temperature $+/-$ $0.8^{\circ} \mathrm{c}$ over arrange of $0^{\circ} \mathrm{C}$ to $+100^{\mathrm{c}} \mathrm{C}$. This sensor draws just 60 microamps from it's supply and acquires a low self-heating capacity. The pin configuration deals with VCC input voltage is $5 \mathrm{v}$ for applications and analog output will be increase to $10 \mathrm{Mv}$ for raise of every ${ }^{\circ} \mathrm{C}$ can range from $-1 \mathrm{~V}\left(-55^{\circ} \mathrm{C}\right)$ to $6 \mathrm{v}\left(150^{\circ} \mathrm{C}\right)$. 


\subsection{Micro Controller}

The Arduino mega 2560 is a microcontroller board based on AT mega 2560.it has 54 digital input/output pins(of which 14 can be used as PWM outputs), 16 analog inputs,4 UART (hard ware serial ports), $16 \mathrm{MHZ}$ crystal oscillator ,a USB connection ,a power jack , an ICSP header and a reset button ,it contains everything needed to support the microcontroller; simply connect it to a computer with a USB cable or power it with AC-to-DC adapter or battery to get started. the Mega is compatible with most shields designed for arduino.

\subsubsection{Features}

Micro Controller: ATmega2560

Advanced RISC Architecture

RAM:8K bites

Internal SRAM:4K bytes

Programmable I/O Lines:86

ADC:16 channel-8 bit

PWM Channels:12-16 bit\&4-8-bit

External Interrupts:8

Programmable watchdog timer with separate on-chip oscillator.

\subsection{Power Supply}

The input of arduino ranges from 7 volts to 12 volts dc $250 \mathrm{~m}$ amps dc adapter. there are different ways to power supply on arduino using USB cable using an ac to de adapter using battery greater than 5V.In this paper we supply arduino with ac to dc adapter plugged into barrel connector of $2.1 \mathrm{~mm}$ diameter the center pin is positive and outer sleeve grounded the barrel connector is supplied an input of $7 \mathrm{~V}-12 \mathrm{~V}$ and this is regulated to $5 \mathrm{~V}$ also by the use of on board voltage regulator when the required power supply is given to arduino the board power on.

\subsection{Control Reset}

Control reset is to execute the entire cycle from beginning.

\subsection{Liquid Crystal Display (LCD)}

LCD screen is an electronic display module and fine a wide range of applications. A16X2 LCD means it can display 16 characters per line and there are such lines. in this each character is displayed in $5 \times 7$ pixel matrix. The schematic diagram of 16X2 LCD is shown in figure. This LCD has two registers namely command and data. The command register stores the command instructions given to the LCD to do the predefined task like initializing it, clearing its screen, setting the cursor position, controlling display etc. The data is the ASCII value of the character to be displayed on the LCD.

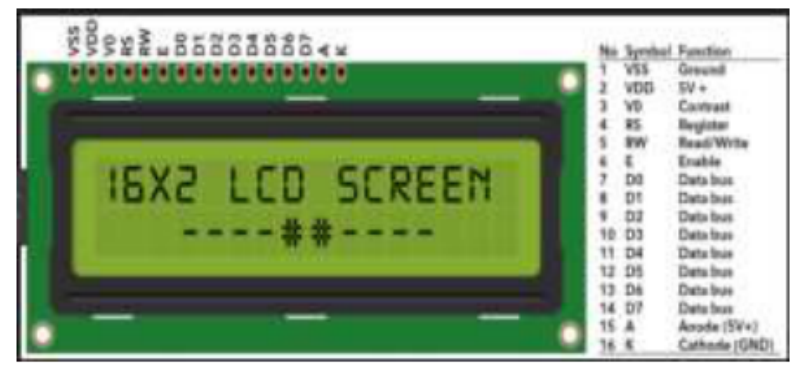

Figure 2 Schematic diagram of $16 \times 2$ LCD 


\subsection{Motor}

DC (direct current) motors convert electrical pulses to mechanical movement. Maximum speed of DC motor is indicated in RPM. The RPM is reduced when moving a load and it decreases as the load increases. The permanent magnet DC motor can be modeled as a device that produces torque proportional to the current flowing through this. It also produced a voltage proportional to the voltage across its terminals. The motor will spin up in speed until the generator portion of the motor model matches the supply voltage .at that point no more current will flow into the motor and it will produce zero torque of course there is some amount of friction so there will be some amount of torque required to spin the motor. Thus some amount of current needed. This current causes a voltage drop across the small series resistance in motor model. This voltage drop takes away from supply voltage and causes the motor to spin a bit slower than the supply voltage would indicate. With output RPM 500rpm, input voltage 12 V, Current 500$600 \mathrm{Ma}$, and shaft length.

\subsection{MAX 232}

The arduino can communicate with the serial devices using its single serial port. the logic levels at which this serial port operates is TTL logics. But some of the serial devices operate at RS 232 logic levels. So in order to communicate the Arduino with modem, a mismatch between the logic levels occurs in order to avoid this mismatch, in other word to match the logic levels, a serial driver is used. A MAX 232 as a serial line driver is shown in figure. The voltage levels of MAX 232 is given as, data transmission from receiver or transmitter logic 0 is from $+3 \mathrm{~V}$ to $+15 \mathrm{~V}$ the TTL voltage is $0 \mathrm{~V}$, data transmission from receiver or transmitter logic 1 is from $3 \mathrm{~V}$ to $-15 \mathrm{~V}$ the TTL voltage is $5 \mathrm{~V}$, Control signals Logic 0 is from $-3 \mathrm{~V}$ to $-15 \mathrm{~V}$ the TTL voltage is $5 \mathrm{~V}$, control signals logic 1 is from $+3 \mathrm{~V}$ to $+15 \mathrm{~V}$ the TTL voltage is $0 \mathrm{~V}$.

\subsection{Global System for Mobile Communication (GSM)}

A GSM modem is a wireless modem that works with a GSM wireless network. A wireless modem behaves like a dial up modem. The main difference between them is that a dial up modem sends and receives data through a fixed telephone line while a wireless modem sends and receives through radio waves. It operates at either the $900 \mathrm{MHZ}$ or $1800 \mathrm{MHZ}$ frequency band. it supports voice calls and data transfer speeds of up to $9.6 \mathrm{kbits} / \mathrm{sec}$. Together with the transmission of SMS the GSM modem comes with a serial interface which the modem can be controlled using AT command interface. The interfacing of GSM modem with the microcontroller is shown in figure .AT commands are used to control the MODEMS. since one of the main objective for this application is to show how to send the message, only a subset of AT command set needs to be implemented. The AT commands are given to the GSM modem with the help of PC or Controller.

\subsection{Global Positioning System (GPS)}

The GPS is a satellite-based navigation system that sends and receives radio signals. a GPS receiver acquires these signals and provides the user with information. Using GPS technology one can determine, and portable system which accurately detects the location. The GPS receiver used here is Sky Traq Venus 6 GPS module ST22 which is having TTL logics and also interface as option. This GPS is used to track the position of the vehicle after the emergency brake is applied. This application is used only after the vehicle is stopped. The Specifications of receiver is 65 channels $-1 \mathrm{~Hz}$ rate with operating voltage 5 volts dc and baud rate of $9600 \mathrm{bits} / \mathrm{s}$. 


\section{WORKING}

Input of arduino containing pulse sensor and temperature sensor and LCD by connecting adaptor power supply with voltage to the arduino simultaneously it is taking the input from pulse sensor and temperature sensor. In normal conditions the temperature sensor will display temperature on LCD, and pulse sensor will display heart rate in BPM (bits per minute) on LCD. In abnormal condition the pulse sensor range will be (heart rate is greater than $76 \mathrm{bpm}$ is high risk of heart attack) in BPM, if that threshold range will exceeds the car control will be under taken by arduino and the car ignition stopped with the help of relay and DC motor, simultaneously the car horn will buzz continuously for help from nearby people to save that person in car who got heart attack, and also the arduino sense the GPS location to the phone number of doctors and family members as a SMS through GSM and GPS devices which are connected to the arduino at output and the SMS will be converted to voice message along with GPS location of vehicle, and An automatic call will be allotted to emergency number(108 in INDIA) for help through mobile phone. After any person approaches and press the RESET button which is connected to the controller the whole system has been RESET.

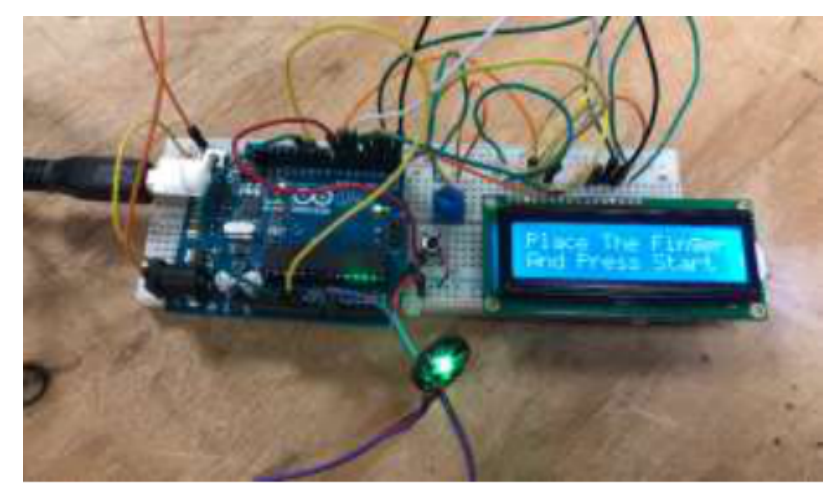

Figure 3 Results

\section{CONCLUSION}

Many are dying with heart attack if a person is travelling alone and got heart attack there is more possibility it may lead to death. Our paper is one touch lifesaving system with this we can save a person life if he is alone and got heart attack the whole system will get activated within seconds and save the life with the help of arduino which is placed in car by sending SMS to family and doctors and self-calling is made by arduino to emergency number (108 in INDIA) for help. From this we can reduces the chance of death and can save the person life.

\section{REFERENCES}

[1] Santhosh B.Patil, Rupal M.Walli, "Design and Development of Fully Automatic At89c52 Space Based Low Cots Embedded System For Rail Tracking", International Journal of Electronic and Communication and Soft Computing Science and Engineering, Volume 1, Issue 1, pp.9-14.

[2] ITSR, Driver Safety Systems Discussion Paper, Australia/new south wales independent transport safety regulator: Sydney, 2006, p.32.

[3] Rajkamal, Embedded System Architecture Programming and Design, tata MC Graw hill publisher $2^{\text {nd }}$ edition, 2008.

[4] Sky Traq Venus 6 GPS Module ST22 Space Sheet. 
[5] Chiranjeevini Kumara B and Rajashekar K, Implementation of SMS Based Heartbeat Monitoring System Using PSOC Microcontroller, International Journal of Electronics and Communication Technology, Vol 2, pp.58-61, Dec 2011.

[6] Rajani Kumari.I, and Krishna Kishore.G, A New Method to Prevent Accidents in Railways Using Microcontroller Based on GSM and GPS Technology, International Journal of Electronics and Communication Engineering and Technology. 2013, Volume 4, Issue 4, pp.272-282.

[7] Chaya Khandelwal S and Manish Patil.M, Implementation of Patient Monitoring System Using GSM Technology, International Journal of Electronics and Communication Technology, 2013, Volume 4, Issue 1, pp.18-24

[8] Jaiee Sitaram Adivarekar, Amisha Dilip Chordia, Harshada Hari Baviska, Pooja Vijayaher, Shraddha Gupta, Patient Monitoring System Using GSM Technology, International Journal of Mathematics and Computer Research, 2013, Vol 2, Issue 2, pp.73-78

\section{AUTHOR PROFILE}

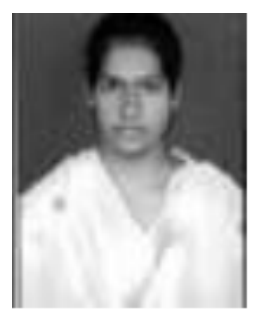

Mrs.I.Rajani Kumari, Assistant Professor in Department of Electronics and Communication Engineering, Sanskrithi School of Engineering, Puttaparthi, India. She has received her B.Tech degree from Sri Sarathi Institute of Engineering and Technology, Nuzivid, A.P, India. She obtained M.Tech degree from Bapatla Engineering College, Bapatla, A.P, India. Her main interesting areas are Signal Processing, Embedded Systems, VLSI.

Miss.Dv.Swapna, Under Graduate student of Electronics and communication Engineering, Sanskrithi School of Engineering, Puttaparthi. Her main Intrested Areas are Embedded Systems and VLSI. 